\title{
Estimating body mass from the astragalus in mammals
}

\author{
Takehisa Tsubamoto \\ Acta Palaeontologica Polonica 59 (2), 2014: 259-265 doi: http://dx.doi.org/10.4202/app.2011.0067
}

Astragalar fossils have been intensively studied as an indicator of the functional morphology and phylogenetic relation-ships of mammals. However, relatively few studies have investigated the relationship between astragalar size and body mass, usually with a focus on a particular taxonomic group. Here, univariate and multiple regression models are used to analyze the relationship between astragalar size and body mass based on an extensive sample of extant land mammals (11 orders, 48 species, 80 individuals; body mass ranging from $18 \mathrm{~g}$ to $3.4 \mathrm{t}$ ). The analyses revealed the size of the tibial trochlea to be a better predictor of body mass than the total size of the astragalus. Based on these results, estimates of the body mass of several Paleogene land mammals were calculated and compared to those of previous studies. Thus, for ex-ample, the body mass of "Baluchitherium", the largest terrestrial mammal known to date, was estimated at about 10-15 t.

Key words: Mammalia, astragalus, talus, regression analysis, body mass estimate, Paleogene.

Takehisa Tsubamoto [sorlestes@msc.biglobe.ne.jp], Great Ape Research Institute, Hayashibara Co., Ltd., 952-2 Nu, Tamano 706-0316, Japan and Hayashibara Museum of Natural Sciences, 4382-4 Shirimi, Oku-cho, Setouchi 701-4212, Japan.

This is an open-access article distributed under the terms of the Creative Commons Attribution License (for details please see creativecommons.org), which permits unrestricted use, distribution, and reproduction in any medium, provided the original author and source are credited. 
